\title{
La Casa da Flor, experimento, poesía y memoria: \\ una mirada museística*
}

\author{
THE FLOWER HOUSE, EXPERIMENT, POETRY, AND MEMORY: \\ A MUSEISTIC APPROACH
}

CASA DA FLOR, EXPERIMENTO, POESIA E MEMÓRIA:

UM OLHAR MUSEAL

\section{Mario Chagas** \\ Danielle Maia Francisco *** \\ Traducción: \\ Juan Carlos Arias \\ y José Alejandro López ****}

Cuadernos de Música, Artes Visuales y Artes Escénicas

/ Volumen 12 - Número 2 / Julio - Diciembre de 2017

/ ISSN 1794-6670/ Bogotá, D.C., Colombia / pp. 49-58

Fecha de recepción: 9 de mayo de 2017

Fecha de aceptación: 5 de junio de 2017

Disponible en línea: 28 de agosto de 2017

doi:10.11144/Javeriana.mavae12-2.Icdf

* Artículo de reflexión.

* Poeta, museólogo, maestro en Memoria Social, doctor en Ciencias Sociales. Profesor del Programa de Pós-Graduação como ganhar dinheiro em casa em Museologia e Patrimônio de la Universidade Federal do Estado do Rio de Janeiro.

** Historiadora, maestra en Museología y Patrimonio por Programa de Pós-Graduação como ganhar dinheiro em casa em Museologia e Patrimônio de la Universidade Federal do Estado do Rio de Janeiro.

*** Profesores del Departamento de Artes Visuales de la Pontificia Universidad Javeriana de Bogotá. 


\section{Resumen}

La Casa da Flor es una obra de arquitectura espontánea ubicada en São Pedro da Aldeia en el estado de Rio de Janeiro (Brasil). Fue diseñada y construida por Gabriel Joaquim dos Santos entre 1912 y 1985 a partir de materiales reciclados de diversa procedencia. Este artículo propone pensar la Casa da Flor como una casa museo desde la conjunción de diversos campos del conocimiento, como la historia, la memoria, el arte, la antropología, la sociología y la educación. Esta aproximación museística permite, en primer lugar, comprender su singularidad y complejidad desde la presencia simultánea de nociones diversas, como sueño e imaginación, memoria y creación, museo y patrimonio, poesía y política, inspiración e incomodidad. Y, en segundo lugar, comprender la Casa da Flor como la encarnación de la multiplicidad de las relaciones que afectan los campos de construcción, tensión y transformación de la museología contemporánea y de las dinámicas de los procesos museísticos hoy.

Palabras claves: Casa da Flor; museo; museología; casa museo, arquitectura espontánea.

\section{Abstract}

TThe Flower House is a work of spontaneous architecture in the city of São Pedro da Aldeia, Rio de Janeiro, Brazil. It was designed and built by Gabriel Joaquim dos Santos from 1912 to 1985 , using recycled materials from different sources. This article attempts to reflect on the Flower House as a house museum from the convergence of different fields of knowledge such as history, memory, arts, anthropology, sociology, and education. This museistic approach allows us to understand, on the one hand, the singular and complex character of the house underlying the simultaneous presence of such diverse notions as dream and imagination, memory and creation, museum and heritage, poetry and politics, inspiration and discomfort. On the other hand, to comprehend the Flower House as the incarnation of multiple relations affecting the fields of construction, tension and transformation within contemporary museology, and museistic processes today.

Keywords:Flower House; museum; museology; house museum; spontaneous architecture

\section{Resumo}

A Casa da Flor é uma obra de arquitetura espontânea localizada em São Pedro da Aldeia no estado do Rio de Janeiro, Brasil. Foi desenhada e construída por Gabriel Joaquim dos Santos entre 1912 e 1985 com materiais reciclados de procedência diversificada. Este artigo propõe pensar a Casa da Flor como uma casa-museu desde a conjunção de diversos campos do conhecimento, tais como a história, a memória, a arte, a antropologia, a sociologia e a educação. Esta aproximação museal permite, em primeiro lugar, compreender sua singularidade $e$ complexidade dadas pela presença simultânea de noções diversas como sonho e imaginação, memória e criação, museu e patrimônio, poesia e política, inspiração e incomodidade. E, em segundo lugar, compreender a Casa da Flor como a encarnação da multiplicidade das relações que afetam os campos de construção, tensão e transformação da museologia contemporânea e das dinâmicas dos processos museísticos hoje.

Palavras chave: Casa da Flor; museu, museologia; casa museu; arquitetura espontânea 


\section{INTRODUCCIÓN}

La naturaleza del tiempo ha sido uno de los enigmas de la humanidad. Se sabe y no se sabe lo que es el tiempo. Poetas, filósofos, historiadores y científicos se inclinan hacia la materia del tiempo. Para algunos, el tiempo es flujo, sucesión, continuidad; para otros, el tiempo es, y solo es; para otros, el tiempo todavía es ilusión, es "maya" (imagen ilusoria), parece que es, pero no es; para otros, en fin, el tiempo es un dios o un ente absoluto.

Sabiendo y no sabiendo lo que es el tiempo, admitiendo que él puede ser flujo, ilusión, un absoluto y lo que es, queremos afirmar que las dimensiones cultural, educacional, social, política, económica y espacial de la Casa da Flor adquieren sentido y se articulan en su dimensión temporal. El tiempo es la sustancia de la que la Casa está hecha.

La Casa da Flor, situada en el municipio de São Pedro da Aldeia (Rio de Janeiro), fue reconocida en 1987 por el Instituto Estadual do Patrimônio Cultural en la categoría de patrimonio histórico y cultural y, en 2016, fue reconocida como patrimonio cultural en el ámbito federal por el Instituto do Patrimônio Histórico e Artístico Nacional.

La Casa da Flor, desde nuestro punto de vista, tiene la vocación para encarnar la complejidad de las relaciones que afectan los campos de construcción, tensión y transformación de la museología contemporánea y de las dinámicas de los procesos museísticos. Por este sendero, podemos comprenderla como una casa museo, una casa que fue construida como una obra de arte o como un artefacto cultural, una casa que es al mismo tiempo monumento y documento y que, por todas estas razones, fue elevada a la categoría de patrimonio y que hoy se encuentra en proceso de resignificación y apropiación cultural.

La Casa da Flor (por más singular que sea), de manera similar a otras casas museos, exhibe una dramaturgia de memoria capaz de afectar, emocionar y quebrar barreras racionales, provocar imaginaciones, sueños y encantamientos, rasgar las fronteras entre objetividades y subjetividades y, además, manipular objetos, ideas, colores, formas, número, textos, sonidos, luces y espacios revisando la producción de narrativas con un extraordinario acento lírico (Chagas 2009, 13).

Este artículo, aunque basado en el terreno de la museología, se interesa por establecer un diálogo con los estudios de la historia, la memoria, el arte, la antropología, la sociología, la educación, y otras áreas del conocimiento. Ese diálogo permite una mejor comprensión de la Casa da Flor a lo largo del tiempo, y de su significado en el mundo contemporáneo, especialmente respecto de las esferas municipal, estatal y federal.

Hoy, la Casa da Flor ocupa un lugar prominente extraño y paradójico en el imaginario social del municipio donde se localiza. Ella es, al mismo tiempo, amada y odiada, endiosada y satanizada, bien y mal querida, protegida y dejada a la buena de dios. Todo esto hace de esta casa un lugar privilegiado para los estudios sobre la memoria, el museo y el patrimonio.

La comprensión de la Casa da Flor como un museo nos coloca de frente con el entendimiento del museo en la actualidad. A fin de cuentas, ¿qué es un museo hoy?

Incluso sin tener la intención de dar una respuesta definitiva y acabada, podemos decir que museo es una palabra, una institución, un fenómeno (o hecho) social, un concepto, una práctica social, y muchas cosas más. No vamos a hacer aquí una arqueología de la palabra museo, pero consideramos importante señalar que sobre ella existen diversas capas de sentido. No vamos a examinar la institución museo, vamos apenas a señalar que ninguna institución es obvia, todas están compuestas por personas y se constituyen a partir de relaciones sociales. 
No vamos tampoco a analizar el museo como fenómeno (o hecho) social, sino a señalar que esa comprensión durkheimiana es una entre tantas otras posibles acerca de los museos.

Admitir la posibilidad de pensar los museos como conceptos y prácticas sociales implica aceptar que existen determinadas características que permiten identificarlos y comprenderlos en movimiento en la sociedad, lo cual, a su vez, abre caminos para la delimitación museística de la Casa da Flor.

\section{LA CASA DA FLOR: CAPAS Y CAPAS DE TIEMPO}

La Casa da Flor es obra de arte, es poesía, es arquitectura, es monumento, es documento y es un buen ejemplo de articulación, que patrimonio y museo posibilitan, entre mundos y culturas diferentes, entre memorias y experimentos diversos.

La disgregación subjetiva y social a la que son sometidos los individuos negros en Brasil fue transformada por Gabriel Joaquim dos Santos en un modo diferente y creativo de expresarse. Este arquitecto popular se incluye, con una obra singular y poética, en el grupo de los artistas constructores de imaginarios insólitos, fantásticos y, en ocasiones, surreales. Artistas que rompieron con los patrones tradicionales y crearon estéticas y formas poco comunes basadas en una inventiva libre de modelos y cánones. Entre estos artistas, se encuentran Ferdinand Cheval' (1836-1924), Antoni Gaudí2 (1852-1926) y Antonio Virzi ${ }^{3}$ (1882-1954). ${ }^{4}$

Hijo de una india y de un exesclavo negro, Gabriel Joaquim dos Santos nació en Cabo Frio en 1892 (cuatro años después de la abolición de la esclavitud), y murió en 1985, también en Cabo Frio. Seu Gabriel (Don Gabriel), como fue conocido, dedicó 73 años de su vida, que no fue corta, a la construcción de una casa. ${ }^{5}$

La Casa da Flor — producción arquitectónica de una vida entera- carga las marcas del tiempo, la fuerza aglutinante de una casa museo y la generación de beneficios culturales, sociales, políticos y económicos para la población de la Região dos Lagos (Rio de Janeiro), que comprende los municipios de Armação dos Búzios, Arraial do Cabo, Cabo Frio y São Pedro da Aldeia. En esta casa, "muy agraciada", ${ }^{6}$ en el sentido de ser portadora de gracia, y plena de potencia política, están articuladas la dimensión cultural, la imaginación poética de un sujeto creador y la memoria social de una región.

Pensar la Casa da Flor desde una mirada museística, aceptando los signos y las marcas de vida y de experiencia que allí están grabadas, puede contribuir a la valorización de una museología que, más allá de un régimen de normas y procedimientos técnicos, desenvuelve una perspectiva comprensiva, sin perder su potencia crítica.

Las investigaciones realizadas para subvencionar el registro de la Casa da Flor en la categoría de patrimonio estatal indican que en 1912, Seu Gabriel Joaquim inició la construcción de la obra de arte que mantendría en proceso hasta el final de su vida. ${ }^{7}$ Se trata de una pequeña casa y de una extraordinaria obra de arte compuesta por trozos de cerámica, loza, porcelana, vidrio, ladrillo, y de toda una serie de materiales y objetos considerados "inútiles" y destinados a la basura. Viejas baratijas, lámparas quemadas, conchas, pequeñas piedras, cadenas, tapas de metal, tubos, luces de automóviles y muchos otros objetos fueron recogidos y reutilizados. En la obra de Seu Gabriel Joaquim dos Santos, hay una dimensión poética que dialoga con muchas otras poéticas contemporáneas y que, de modo especial, conversa con Manoel de Barros cuando señala: "Todo lo que nuestra civilización rechaza, desprecia y se mea encima, sirve para hacer poesía" (1997, 19). Y también afirma: "El poema es, antes que todo, un inutensilio" (Chagas 1982, 23). 
La Casa da Flor lidia con inutensilios y, por tanto, con poéticas que pueden ser percibidas en su discurso arquitectónico formal, así como en su gramática decorativa, compuesta de detalles y fragmentos que no fueron originalmente producidos para la composición de estructuras arquitectónicas. La Casa es, ella misma, un artefacto compuesto de artefactos coleccionados y resignificados, retirados del río del tiempo y colocados en otra escala temporal. El examen de la decoración del interior de la Casa da Flor puede revelar aspectos de la vida subjetiva, de la memoria y de la poética de Seu Gabriel, pero también presenta marcas y señales de la vida social de los grupos que ocupaban los territorios por donde el artista se desplazaba. En este sentido, las paredes de la Casa revestidas por varios objetos presentan textos o hipertextos que permiten o remiten lecturas diferenciadas. Ese es el caso, por ejemplo, de un emblema de Volkswagen empotrado en una de las paredes, y que nos remite a asuntos que ponen en discusión las apropiaciones artísticas, las antropofagias culturales, los reciclajes, las resignificaciones, así como el diálogo entre la industria y lo artesanal, el capital y el trabajo, lo global y lo local, lo plural y lo singular, la basura y el lujo.

De algún modo, la Casa construida por Seu Gabriel presenta — por medio de sus muebles, de sus paredes, de su argamasa, de su discurso formal - una cierta manera de ver el mundo. El arquitecto, constructor de su propia Casa, sueña y colecciona, construye y sueña, construye y colecciona una gama extraordinaria de artefactos.

Seu Gabriel Joaquim dos Santos, arquitecto-artista-coleccionista, vive, como diría Walter Benjamin, "una tensión dialéctica entre los polos del orden y el desorden". La existencia del coleccionista, según Benjamin, está sujeta a

una relación muy misteriosa con la propiedad [...] a una relación con las cosas que no destaca su valor funcional o utilitario, su utilidad, sino que las estudia y las ama como el palco, el escenario de su destino. El mayor atractivo del coleccionista es encerrar cada pieza en un círculo mágico donde ella se fija cuando pasa por ella la última excitación, la excitación de la compra [o de la adquisición, ${ }^{8}$ decimos nosotros, en busca de mayor precisión conceptual). (1987, 228)

El trabajo sistemático de Seu Gabriel, dedicado —-lo decimos de nuevo— por 73 años a la construcción de la Casa da Flor (sinfonía inacabada), a la formación de una obra colección capaz de ir más allá de la muerte del autor, a la fabricación de un artefacto-hecho-de-artefactos, implicó la producción de un patrimonio que, bañado en las aguas de la temporalidad, se convirtió en referencia cultural para la ciudad de São Pedro da Aldeia y para el estado de Rio de Janeiro. La Casa da Flor, habiendo sido construida por un artista que nació y vivió al margen, o cuando mucho bordeando y bordando los límites entre el sistema y "el otro lado del río," ${ }^{9}$ es hoy reconocida como un bien simbólico importante para la afirmación de identidades y la valorización de la memoria y de los saberes de las comunidades de la denominada Região dos Lagos. 


\title{
BREVE LECTURA DEL SILENCIO
}

La museología, desde nuestra perspectiva, puede ser comprendida como un campo y, en ese sentido, no es de gran interés discutir si ella es arte, ciencia o técnica. Entendida como campo, su configuración se sitúa en la relación entre los seres humanos, los objetos calificados y el espacio socialmente constituido. En ese sentido, el museo es espacio de relación, de encuentro, de vivencia y convivencia. Más allá de las diferencias entre los museos, de la museodiversidad, más allá de los museos ortodoxos, de los nuevos museos y de los museos sociales, se impone una pregunta: ¿qué hacer con los museos?

Para responder a este interrogante, es posible afirmar que los museos pueden ser comprendidos como prácticas sociales puestas al servicio de la sociedad y de su buen vivir, y que tienen como características principales

\begin{abstract}
el trabajo permanente con el patrimonio cultural integral; el uso del patrimonio cultural como recurso educativo; la presencia de archivos (heredados o construidos) y de exposiciones (de larga, media o corta duración) abiertas al público, con el objetivo de propiciar la construcción social de la memoria, la percepción crítica de la realidad cultural brasileña, el estímulo a la producción de conocimiento, nuevas oportunidades de ocio y la vocación por la comunicación, la investigación, la interpretación, la documentación y la preservación de testimonios culturales y naturales. (Política Nacional de Museus2007)
\end{abstract}

En este punto del artículo, ya es posible comprender que la Casa da Flor no presenta simplemente las características citadas (bien sea en acto o en potencia), sino que también se inserta en el grupo especial de prácticas e instituciones que operan en favor de una mirada museística que se ampara en una nueva perspectiva museológica, en una museología social o, incluso, en una museología crítica.

Todo esto permite entender que la Casa da Flor, comprendida desde un punto de vista museístico, está en sintonía dialógica con el ideario de la Mesa Redonda de Santiago de Chile, la cual tuvo lugar en mayo de 1972, teniendo por foco la función social de los museos.

La Mesa Redonda de Santiago de Chile, que se llevó a cabo hace cuarenta años, apuntaba a la necesidad de que los museos estuvieran conectados con su tiempo y que trabajaran radicalmente en favor de la sociedad y la comunidad en la que estaban insertos.

Las poéticas y políticas museísticas están presentes en el mundo occidental desde la aparición de las primeras prácticas e instituciones y, por tanto, desde por lo menos el siglo XVII. ${ }^{10}$ A partir de las décadas de 1960 y 1970, una renovación especial de estas poéticas y políticas entró en acción. Nuevas experiencias se desarrollaron, y las prácticas que hasta entonces estaban situadas en los márgenes del sistema museístico fueron desplazadas de la periferia hacia el centro de las discusiones, o de modo incluso más radical: gradualmente, las nociones de periferia y centro museístico fueron deconstruidas y la potencia transformadora de los museos pasó a ser accionada por grupos sociales diferenciados. Este es el origen de las denominadas nueva museología, ecomuseología, museología popular, museología crítica, museología social, sociomuseología, y otras denominaciones. 
La Casa da Flor posee la fuerza agregadora de una casa museo y genera beneficios sociales y políticos para la población de la Região dos Lagos en el estado de Rio de Janeiro. Esta Casa, teniendo como referencia la mirada sensible de un arquitecto popular y espontáneo, constituye un arco de lenguaje abarcante, en diálogo con los movimientos culturales, sociales y políticos que eclosionaron en la segunda mitad del siglo XX.

Sobre esta Casa tan singular acechó y todavía acecha cierto silencio, especialmente respecto de las gestiones políticas en el municipio de São Pedro da Aldeia. La importancia de la Casa es reconocida y presumida especialmente por los que vienen de fuera, por los extranjeros, mientras que entre los locales frecuentemente es silenciada, olvidada, poco valorizada.

Entre el alarde y el silencio se va construyendo alrededor de la Casa da Flor una narrativa muy peculiar. Una narrativa que, a partir de un juego de llenos y vacíos, sonidos y silencios, aceleración y desaceleración, construye otra cosa, otra historia, otras posibilidades cognitivas, afectivas, sensoriales e intuitivas. Es, de ese modo, que se hace posible escuchar la voz del silencio de la Casa da Flor.

El desafío de la musealización de la Casa da Flor, cuyo problema en este artículo apenas está delineado, pasa, desde nuestro punto de vista, por el fortalecimiento de la investigación, de la comunicación y de la conservación, así como por la dinamización de su función social, por la valorización de su capacidad de propiciar sueños y de activar el imaginario individual y colectivo, por el reconocimiento de la singularidad de su lenguaje museístico y, además, por la comprensión de que en los museos, por más diferentes que sean, está en permanente construcción y deconstrucción el tejido de una trenza de tres hilos que envuelve lo poético, lo político y lo pedagógico.

\section{LA EXPERIENCIA DEL MIRAR ES LÍMITE Y DESLÍMITE}

Según Seu Gabriel Joaquim dos Santos, el demiurgo de la Casa da Flor: "Esta casa no es una casa; esto es una historia, es una historia porque fue hecha por pensamiento y sueño". Pensamiento y sueño, conocimiento y emoción, he aquí la explicitación de la materia de la Casa. ${ }^{11}$ Una Casa a la cual miramos y que, al mismo tiempo, impacta nuestro mirar.

Mirar y ser mirado. Mirar y ser mirado por la cosa mirada es una experiencia museística muy fuerte y recurrente. Frecuentemente, se tiene, en los más distintos tipos de museos, la impresión de que el tiempo todo, el tiempo en que se ve, se es visto. Y no se es visto solo por los otros visitantes que vemos y que nos ven; somos vistos por las cosas concretas, por los artefactos materiales, por los objetos que vemos. Desde el fondo del tiempo, desde el fondo de su materialidad, desde el fondo de sus culturas ancestrales o no, ellos nos ven y nos cuestionan, así como nosotros los vemos y los cuestionamos.

La Casa da Flor propicia esta experiencia, ella tiene esta extraordinaria peculiaridad cultural. Sus paredes nos miran desde el fondo del tiempo, el tiempo es su sustancia (Benjamin 2007, 140-141).

Síntesis provisoria: no somos solo sujetos de conocimiento inclinados sobre determinados objetos, sino que somos también objetos en las manos de nuestros aparentes objetos de conocimiento. 
Escogemos nuestros temas de investigación, pero también podemos decir, en ciertos casos, que somos escogidos por ellos: sus peculiaridades, sus extrañezas y sus ritmos nos escogen y direccionan nuestra mirada. En ciertos casos, es preciso entablar una verdadera lucha contra los condicionamientos objetuales. Todo eso para afirmar la libertad, trágicamente condicionada.

En lo cotidiano de nuestras vidas, recibimos y sufrimos las influencias de lo que vemos, de lo que no vemos e imaginamos, de los amigos y de los enemigos, de los familiares, de los conocidos y de los desconocidos. Todas esas influencias, mezcladas con nuestras subjetividades, plantean temas de reflexión e investigación, determinan abordajes y creaciones artísticas, producen equilibrios y desequilibrios.

\section{CONSIDERACIONES FINALES}

Yo tengo un pensamiento vivo.

Gabriel Joaquim dos Santos

La historia de las sociedades humanas puede ser comprendida como un proceso dinámico y dialéctico que lleva en sí mismo el principio de contradicción, el germen del cambio. La realidad no es estática, es dinámica, dialéctica, está en transformación. Los museos no son estáticos, están en movimiento, en cambio; ellos son dialécticos y están sometidos al principio de contradicción.

Tiempo, patrimonio, memoria, arte, creación, museo, comunicación, poética, voz y silencio son categorías que la experiencia con la Casa da Flor permite accionar. Esta experiencia constituye el desafío de lidiar con un patrimonio cultural, cuya vocación museística está impresa en su propio cuerpo como marca de nacimiento.

Las casas museos (sean casas de las clases populares, de las clases medias o de las élites sociales y económicas), en rigor, son casas que salieron de la esfera privada y entraron en la esfera pública o del servicio abierto al público. Dejaron de abrigar personas, pero no dejaron necesariamente de abrigar objetos, muchos de los cuales fueron sensibilizados por los antiguos habitantes de la casa, y hoy sensibilizan en las más distintas direcciones a los visitantes.

Las casas museos y sus objetos sirven para evocar en los visitantes memorias de antiguos habitantes, de hábitos, sueños, alegrías, tristezas, luchas, derrotas y victorias, pero también sirven para evocar memorias de las casas que el visitante habitó y que hoy habitan (Chagas 2009, 15).

"Yo tengo un pensamiento vivo", señalaba Seu Gabriel. Y al decir eso parecía saltar en dirección al futuro. Más allá del fardo, del trabajo en las salinas, Seu Gabriel trajo para su vida y traía a su refugio la interferencia del arte, lo nuevo, la memoria, la creación.

La Casa da Flor continúa siendo eso: sueño e imaginación, memoria y creación, museo y patrimonio, poesía y política, inspiración e incomodidad, la encarnación de un pensamiento vivo y desafiante. 


\section{NOTAS}

1 Cartero francés que vivió en Drôme y pasó treinta y tres años de su vida recogiendo piedras y construyendo su "palacio ideal", ejemplo único de arquitectura espontánea.

2 Arquitecto catalán, nacido en Reus y fallecido en Barcelona, donde su obra fue consagrada y, hasta hoy, es venerada como símbolo de la ciudad y de la potencia creadora de Cataluña.

3 Arquitecto nacido en Palermo (Italia) y fallecido en São Paulo en 1954. Llegó a Río de Janeiro alrededor de 1910 y creó una obra arquitectónica innovadora, expresiva, singular e incendiaria.

4 Es importante señalar que Ferdinand Cheval, Antoni Gaudí, Antonio Virzi y Gabriel Joaquim dos Santos, en alguna medida, fueron contemporáneos.

5 Amelia Zaluar, guardiana del archivo de la Casa da Flor y presidente del Instituto Cultural Casa da Flor.

6 Juego con la expresión muito engraçada. (N. del T.)

7 La inscripción "Casa da Flor - 1923", registrada en una de las fachadas, marcaría, según algunos relatos, el año en que Seu Gabriel, después de un sueño, empezó a incorporar a su arquitectura materiales que destinaban a la basura.

8 Es importante señalar que entre las diferentes formas de adquisición se encuentran la donación, la compra, la permuta y la colecta. No incluimos en esta categoría el saqueo, el hurto o el robo por el carácter criminal de estas prácticas; sin embargo, conviene recordar que ellas han alimentado museos y colecciones.

9 "Al otro lado del río" es un fragmento del último verso del poema "Cisma do velho da favela do formigueiro", que hace parte del libro Agua Salobra de autoría de Mario Chaga, publicado en 2015 por la editorial Espirógrafo.10 Y la primera de su tipo en lo que aún no se conocía como SoHo, sino todavía como Downtown.

10 Debe tenerse en cuenta la importancia de la realización de investigaciones que tengan en consideración otros caminos, otras hipótesis que ayuden a identificar y a pensar prácticas y experiencias que apunten a insurgencias en relación con el modelo museístico colonial.

11 Estevão Silva da Conceição construyó la Casa de Piedra, una de las construcciones más originales de la ciudad de São Paulo que queda en el corazón de la favela Paraisópolis, en el barrio de Morumbí. Es un lugar con arcos salpicados de piedras y paredes cubiertas con todo tipo de objetos, desde platos, tazas y estatuas, hasta máquinas de escribir y teléfonos celulares. Lo que parece más sorprendente es que un hombre que nunca oyó hablar del arquitecto catalán Antoni Gaudí (1852-1926) haya construido algo tan próximo a su estilo. Una especie de Seu Gabriel contemporáneo.

\section{REFERENCIAS}

Abreu, Regina. 1996. A fabricação do imortal: memória, história e estratégias de consagração no Brasil. Rio de Janeiro: Not Avail.

Bachelard, Gaston. 1993. A poetica do espaço. São Paulo: Martins Fontes.

Barros, Manoel de. 1997. “Entrevista exclusiva". Caros Amigos 1 (3): 18-21.

Brasil. 2007. Política Nacional de Museus. Brasília.

Benjamin, Walter. 1987. “Rua de Mão Única". En Obras Escolhidas III. São Paulo: Brasiliense. 
- 1994. Charles Baudelaire: um lirico no auge do capitalismo. São Paulo: Brasiliense.

- 2007. Passagens. Minas Gerais: Editora UFMG.

Bordieu, Pierre. 1996. As Regras da Arte - gênese e cultura no campo literário. São Paulo: Companhia das Letras.

- 2000. Uma História Social do Conhecimento - de Gutenberg a Diderot. Rio de Janeiro: Jorge Zahar Editor.

- 2001. O poder simbólico. Rio de Janeiro: Bertrand Brasil.

Chagas, Mário. 1996. Museália. Rio de Janeiro: JC Editor.

- 2002. "Museu, literatura e emoção de lidar". Cadernos de Sociomuseologia 19 (19).

- 2006. Há uma gota de Sangue em cada Museu - a ótica museológica de Mario de Andrade. Santa Catarina: Editora Argos.

- 2009. A imaginação museal - Museu, memória e poder em Gustavo Barroso, Gilberto Freyre e Darcy Ribeiro. Rio de Janeiro: IBRAM.

- 2013. "A poética das casas museus dos heróis populares". Mosaico 2 (4).

Durkheim, Emile. 1996. As regras do método sociológico. São Paulo: Martin Claret.

Gonçalves, José Reginaldo S. 2007. Antropologia dos objetos: coleções, museus e patrimônios. Rio de Janeiro: Coleção Museu, Memória e Cidadania.

Florentino, Manolo. 1997. Em Costas Negras - uma historia do trafico de escravos entre a África e o Rio de Janeiro. São Paulo: Companhia das Letras.

Holanda, Sergio Buarque de. 1999. Raízes do Brasil. São Paulo: Companhia das Leras.

Lira, Sérgio. 2004. O Museu é a Minha Casa: Para uma Nova Museologia Etno(gráfica). Águas Santas.

Santos, Maria Célia Teixeira Moura. 2008. Encontros Museológicos - reflexões sobre a Museologia, a educação e o museu. Rio de Janeiro: Coleção Museu, Memória e Cidadania.

Santos, Myrian Sepúlveda dos. 2006. A escrita do Passado em museus históricos. Rio de Janeiro: Garamond.

Zaluar, Amélia. 1989. Livro de apontamentos de Seu Gabriel Joaquim dos Santos. Río de Janeiro: Instituto Cultural Casa da Flor. Inédito.

- 2012. A Casa da Flor: tudo caquino transformado em beleza. Folio digital.

\section{Cómo citar este artículo:}

Chagas, Mario \& Francisco, Danielle Maia. 2017. “La Casa da Flor, experimento, poesía y memoria: una mirada museística". Cuadernos de Música, Artes Visuales y Artes Escénicas. 12 (2): 49-58. https://doi.org/10.11144/Javeriana.mavae12-2.Icdf 